\title{
Analysis of energy losses reduction potential on the distribution line of campus building through electric power quality improvement
}

\author{
Andi Pawawoi ${ }^{1}$, Zuheldi $^{2}$, Fajril Akbar ${ }^{3}$, Refdinal Nazir ${ }^{4}$ \\ ${ }^{1,4}$ Department of Electrical Engineering, Universitas Andalas, Indonesia \\ ${ }^{2}$ P3TKEBTKE, Ministry of Energy and Resources, Indonesia \\ ${ }^{3}$ Department of Information System, Universitas Andalas, Indonesia
}

\begin{tabular}{l} 
Article Info \\
\hline Article history: \\
Received May 24, 2019 \\
Revised Jul 7, 2019 \\
Accepted Jul 17, 2019 \\
\hline
\end{tabular}

\section{Keywords:}

Distribution line

Energy losses

Harmonic distortion

Power factor

Unbalanced

\begin{abstract}
In public and commercial buildings, the reduction of electricity consumption activities can be conducted through 3 paths, including improving the quality level of electric power, increasing the efficiency of electrical equipment, and reducing the waste of electric energy use. In this paper, the energy losses reduction potential on the distribution line of Engineering Faculty, Andalas University buildings through electric power quality improvement are analyzed. Power Quality (PQ) variables that considered in this analysis include power factor, unbalance current load and harmonics distortion. Analysis of correlation between PQ variables is required to determine the power loss on the distribution line of buildings. Using data of PQ variables recorded by Fluke Power Analyzer 435 series II, the energy losses of the distribution line without/with PQ improvement for each building is calculated. Analysis results have shown that the reduction potential is proportional to the value of PQ variables. Administrative faculty building with poor power quality has the potential to reduce its energy losses on the distribution line by $52.62 \%$ through power quality improvement. Civil engineering building group with quite good power quality only has the potential to reduce energy losses by $32.81 \%$. Overall, the buildings in this faculty have the potential to reduce energy losses on distribution lines by $34.42 \%$ through its power quality improvement.
\end{abstract}

Copyright $(0) 2020$ Institute of Advanced Engineering and Science. All rights reserved.

\section{Corresponding Author:}

Refdinal Nazir,

Department of Electrical Engineering,

Universitas Andalas

Jalan Dr. Mohammad Hatta, Kampus Limau Manis Padang, Indonesia

Email: refdinalnazir@eng.unand.ac.id

\section{INTRODUCTION}

Three reduction paths of the electric energy consumption can be done in commercial and public buildings, including improving the quality level of electric power, increasing the efficiency of electrical equipment, and reducing the waste of electric energy use. The electricity consumption reduction through the first path is made by reducing energy losses on the distribution network in buildings by the improvement of the quality level of electric power. The reduction pathway of electricity consumption through inefficient replacement of inefficient electric equipment with more efficient equipment has been studied in several kinds 
of literature [1,2]. While reducing consumption of electrical energy through reducing waste of electrical energy can be done through management approach and automation [3, 4]. This analysis is focused on reducing the consumption of electric energy through the path of improving the quality of electric power on the distribution lines in the buildings.

Several events in the power system are often associated with low power quality level, including flicker, voltage sag, unbalance loads, harmonic distortion, and lower power factor [5-8]. Among them were very influential on increasing power losses are lower power factor, unbalanced loads, and harmonic distortion [9-13]. Lower power factor will increase the reactive power or RMS current so that it contributes to the increase of power loss in the phase line. Unbalance in load current will cause an increase in the current in the neutral conductor. It will increase the power losses in the phase line and the neutral conductor. The value of Total Harmonic Distortion (THD) will also increase power loss on the distribution line and the neutral conductor.

In this paper, the energy losses reduction potential on the distribution line of campus buildings through electric power quality improvement is analyzed. Power Quality (PQ) variables that considered in this analysis include power factor, unbalance current load, and harmonics distortion. Based on the recording results of power quality variables data using Fluke Power Analyzer 435 series II, the power loss of the distribution line without/with PQ improvement for each building is calculated.

\section{SYSTEM CONFIGURATION}

The study was conducted on the distribution substation in Faculty Engineering, Andalas University. The configuration of the substation is used as the object of study is shown in Figure 1. The substation built by a transformer $630 \mathrm{kVA}, 20 \mathrm{kV} / 400 \mathrm{~V}$ and 3 distribution lines supplying one load respectively, and one other distribution line supplying 3 loads. The substations distribute power from the utility grid through line $20 \mathrm{kV}$ using NYFGBY cables. Data for each distribution line are shown in Table 1. The load centers comprise 5 buildings Dept. and 1 building faculty. The department building has a lecturer room, laboratories, reading rooms, tutorial rooms, and room service administration. Whereas, the type of equipment that consumes electrical energy are computers, air conditioning, lighting, water pumps, dispensers, fan, as well as laboratory equipment.

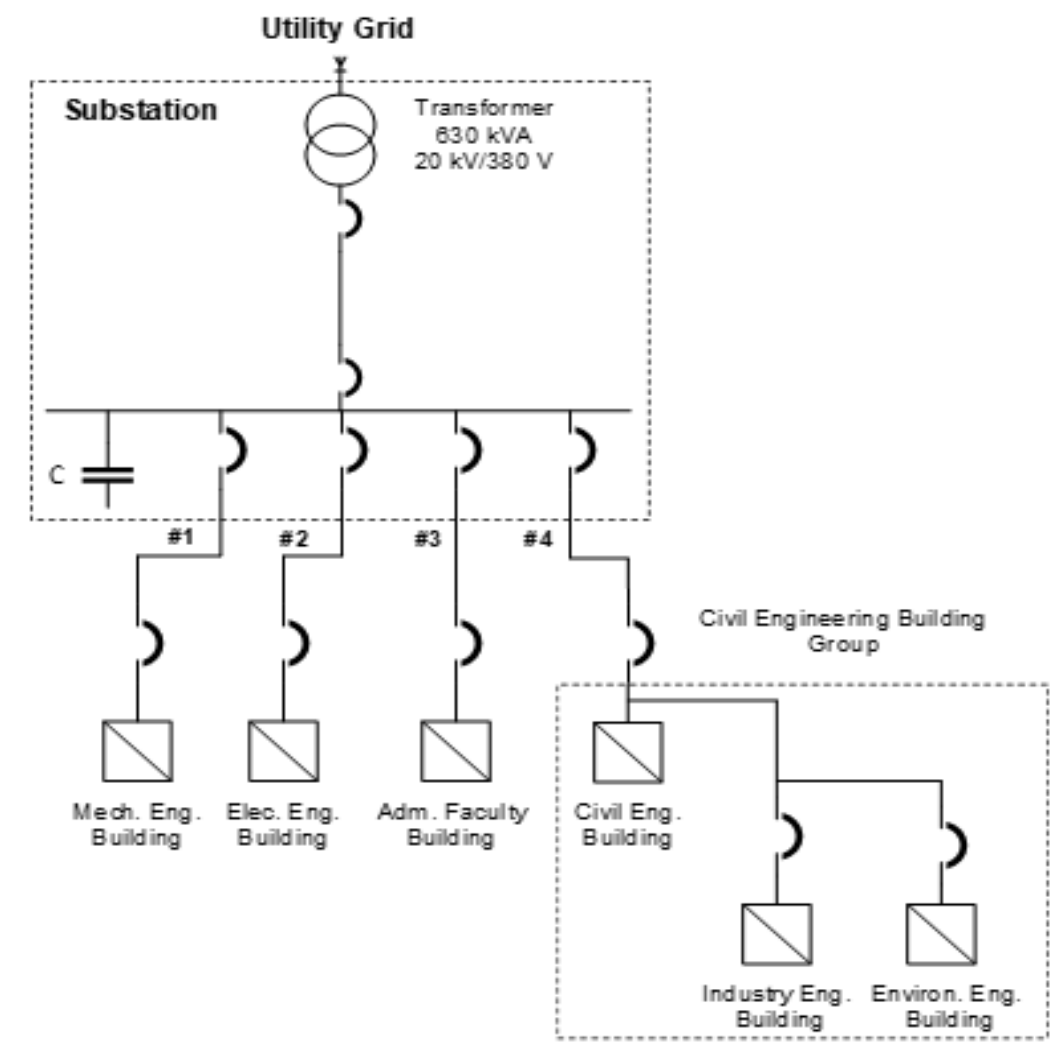

Figure 1. The system configuration of the object study 


\begin{tabular}{|c|c|c|c|}
\hline Lines & Specification of cable & Distance (m) & $R_{\text {Line }}(\Omega)$ \\
\hline \# 1 & NYFGBY 4 x $50 \mathrm{~mm}^{2}$ & $2 \times 112$ & 0.0264 \\
\hline$\# 2$ & NYFGBY 4 x $50 \mathrm{~mm}^{2}$ & $2 \times 48$ & 0.0111 \\
\hline$\# 3$ & NYFGBY $4 \times 50 \mathrm{~mm}^{2}$ & $1 \times 57$ & 0.0260 \\
\hline \#4 & NYFGBY 4 x $95 \mathrm{~mm}^{2}$ & $1 \times 190$ & 0.0441 \\
\hline
\end{tabular}

\section{MEASUREMENT SYSTEM OF POWER QUALITY VARIABLES}

For analysis, the power loads and its power quality variables of measurement results for each building located in the engineering faculty area were carried out using a Fluke Power Log 430-II measuring instrument. This measurement is conducted during one week for each building, and for every 10 minutes, its data is recorded. Thus, for each building, there are 1,008 measurement steps, with an interval of 10 minutes each. In this study, it is assumed that the power load and its power quality pattern will recur periodically for each week. The measurement data were analyzed to obtain characteristic curves of power quality variables (in Section 3) and to examine the effect of power quality on the power loss (in Section 5) and the influence the power quality on the power loss (in Section 5).

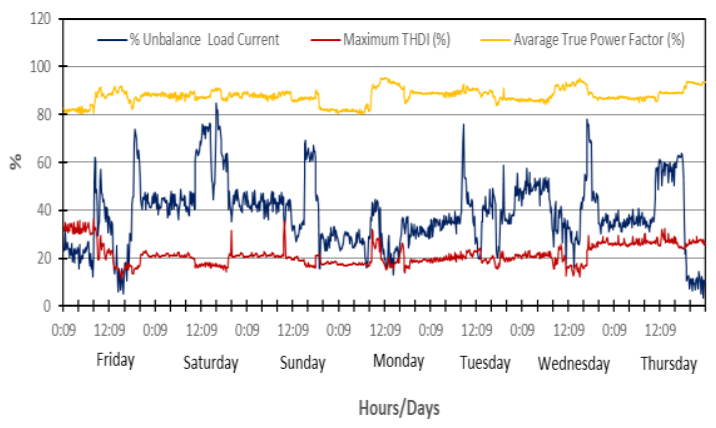

Figure 2. The Characteristics of power quality variables on the distribution line \#1

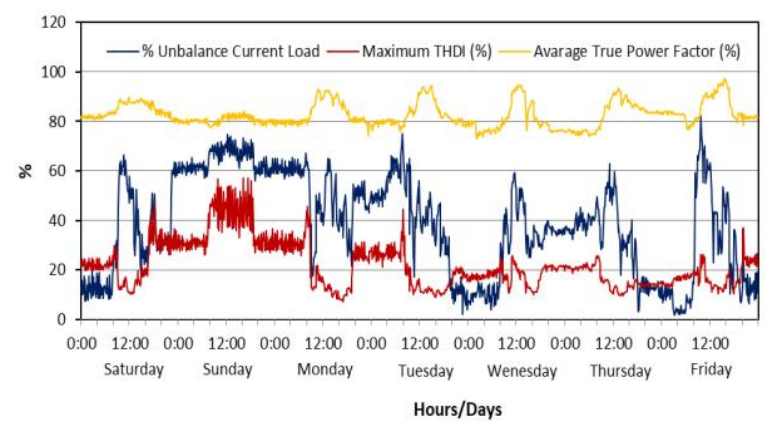

Figure 3. The Characteristics of power quality variables on the distribution line \#2

Figure 2 shows the characteristics of power quality variables for distribution line \#1 (mechanical engineering building). As shown in Figure 2, the average power factor varies between $84 \%$ to $91 \%$, which its lowest values were occurring outside working hours. The pattern of characteristics for load current unbalance are very fluctuating and irregular, with the percentage of unbalance varying from $3 \%$ to $80 \%$. Also, the values of THD's load currents can vary from $8.5 \%$ to $56 \%$, with the lowest THD values occurring during working hours. It happens because outside the working hours, the load that dominated by energy saving lamp with high harmonic distortion. The characteristics of power quality variables for the load power of electrical engineering building (distribution line \#2) is showed in Figure 3. As shown in this figure, the average value of the power factor varies between $80.0 \%$ to $95.3 \%$, with its average value of $87.7 \%$. The maximum $\mathrm{THD}_{\text {I }}$ of three-phase loads current fluctuates from $11.3 \%$ to $36.5 \%$, with its average value of $21.5 \%$. While, the unbalance of load current varies wide enough from $3.3 \%$ to $84.7 \%$, with its average value of $38.6 \%$.

Figure 4 presented the characteristics of power quality variables for the load power of the faculty administration building (distribution line \#3). The variation of average power factor in this building is almost similar to the previous buildings. However, the unbalance of the load current is very fluctuating from $0 \%$ to $127.9 \%$, with its average value of only $34.5 \%$. The percentage of the unbalance exceeds the value of $100 \%$ occurs because the deviation of the load current on one of phase is large enough; its value exceeds the average value of load current. While, the maximum $\mathrm{THD}_{\mathrm{I}}$ of three-phase load current varies from $16.3 \%$ to $73.3 \%$, with its average value of $44.3 \%$. The characteristics of power quality variables for the load power of civil engineering building groups (distribution line \#4) is showed in Figure 5. In this building, the variation for average power factor and maximum $\mathrm{THD}_{\mathrm{I}}$ is normal. However, this distribution line has the lowest average power factor among the four existing lines, which is $80.9 \%$. Nevertheless, the load of this group of buildings has the lowest average value of THD harmonic current and unbalance load current, which is only $10.15 \%$ and $21.27 \%$ respectively. 


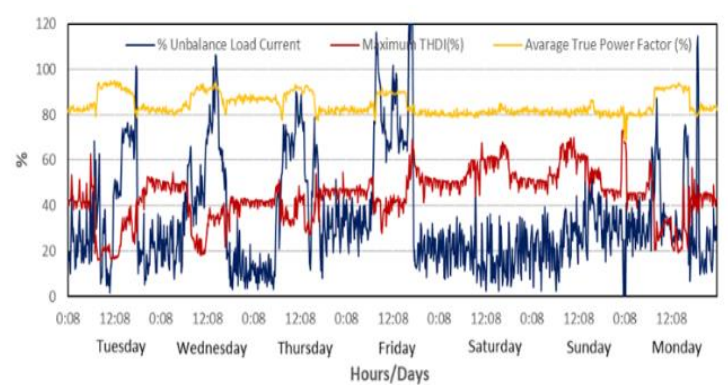

Figure 4. Characteristics of power quality variables on the distribution line \#3

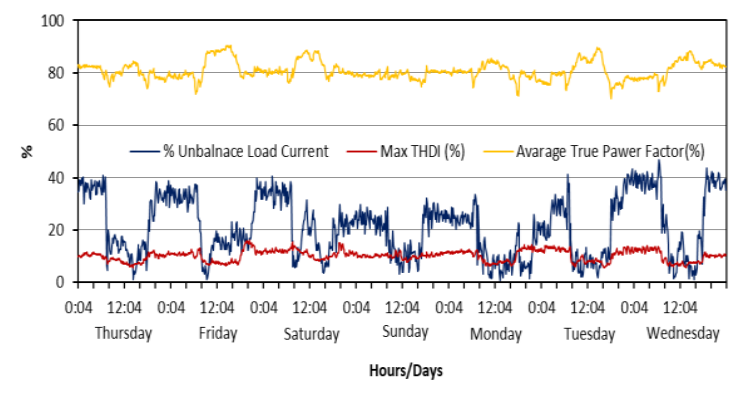

Figure 5. Characteristics of power quality variables on the distribution line \#4

\section{ANALYSIS OF CORRELATION BETWEEN THE POWER QUALITY VARIABLES WITH POWER LOSSES}

The distribution line power loss that happened in the configuration system, as shown by Figure 1 consists of phase line power loss and neutral conductor power loss. The quantity of power loss for each component is affected by the variables of power quality, such as total harmonics distortion, power factor, and unbalance conditions $[14,15]$. Figure 6 shows the correlation between power loss and the variables of power quality. As shown in this figure, the total harmonic distortion will affect all power loss component in the system.

Meanwhile, the power factor will influence phase line power loss. The unbalance conditions will affect neutral conductor power loss and phase line power loss. Also, the harmonic distortion negatively impacts the value of the power factor and unbalanced current.

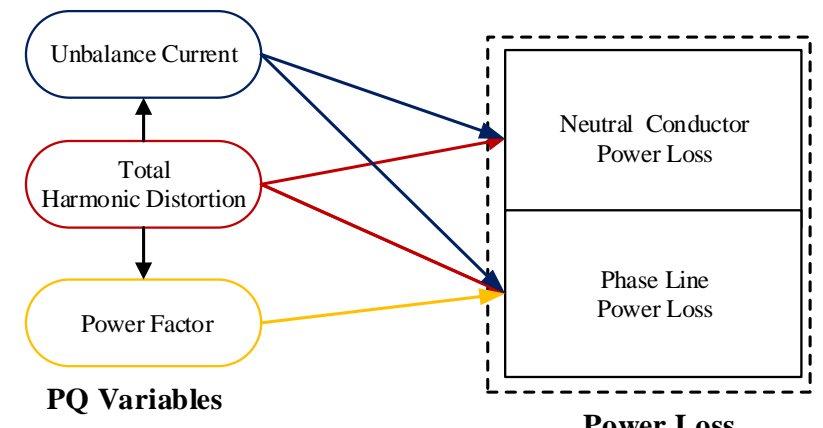

Figure 6. The relationship between power loss and the variables of power quality

\subsection{Harmonics Distortion Effect On Power Loss}

The use of electronic equipment, such as Personal Computer (PC), Energy-Saving Light (ESL), Uninterruptible Power Supply (UPS), etc., will cause harmonic distortion in current and voltage [16-18]. The level of current waveform deviation due to harmonic distortion is usually measured with Total Harmonic Distortion (THD) for each phase and step measurement, which is defined as (5):

$$
T H D_{\mathrm{I}}(\mathrm{i})=\frac{\sqrt{\sum_{\mathrm{h}=2}^{\mathrm{n}} I_{\mathrm{h}}^{2}(\mathrm{i})}}{I_{1}(\mathrm{i})} x 100
$$

where,

$T H D_{\mathrm{I}}(\mathrm{i})=$ Total Harmonic Distortion of current for the $\mathrm{i}^{\text {th }}$ measurement step (\%)

$I_{\mathrm{h}}(\mathrm{i})=\mathrm{h}^{\text {th }}$ order harmonic current for the $\mathrm{i}^{\text {th }}$ measurement step (A rms)

$I_{1}(\mathrm{i})=$ fundamental current for the $\mathrm{i}^{\text {th }}$ measurement step (A rms)

The total RMS value of the line current containing harmonic components is expressed by (4): 


$$
I_{\mathrm{rms}}(\mathrm{i})=\sqrt{\sum_{\mathrm{h}=1}^{\mathrm{n}} I_{\mathrm{h}}^{2}(\mathrm{i})}
$$

where $I_{\text {rms }}$ (i) is the RMS current for the $\mathrm{i}^{\text {th }}$ measurement step (rms).

From (1) \& (2), the relationship between $I_{\mathrm{rms}}(\mathrm{i})$ and $T H D_{\mathrm{I}}(\mathrm{i})$ can be expressed as:

$$
I_{\text {rms }}(\mathrm{i})=I_{1}(\mathrm{i}) \sqrt{1+\left\{\frac{T H D_{\mathrm{I}}(\mathrm{i})}{100}\right\}^{2}}
$$

As shown by (3), the total value of the arms current will increase with the rise in the value of $T H D_{\mathrm{I}}$.

The total value of rms line current for the three-phase line will determine the quantity of phase line power loss, as shown by the following equation:

$$
P_{3 \text { phase-loss }}(\mathrm{i})=\left\{I_{\text {rms }- \text { Aphase }}^{2}(\mathrm{i})+I_{\text {rms-Bphase }}^{2}(\mathrm{i})+I_{\text {rms -Cphase }}^{2}(\mathrm{i})\right\} R_{\text {line }}
$$

where $R_{\text {line }}$ is the line resistance that given in Table 1 .

\subsection{Lower Power Factor Effect On Power Loss}

The use of inductive loads, such as water pumps, air conditioning, fan, etc., will cause a decrease in the power factor of the system. The decline in power factor will cause an increase in the line current, as shown by the following equation:

$$
I_{L}(\mathrm{i})=\frac{P_{\mathrm{L}}(\mathrm{i})}{\sqrt{3} V_{\mathrm{LN}}(\mathrm{i}) \operatorname{TPF}(\mathrm{i})}
$$

where:

$T P F(\mathrm{i})=$ True Power Factor for the $\mathrm{i}^{\text {th }}$ measurement step

$P_{\mathrm{L}}(\mathrm{i})=$ Three-phase power load for the $\mathrm{i}^{\text {th }}$ measurement step (Watt)

Increased in the current phase line as a result of a decrease in power factor will cause an increase in power losses on the phase line.

In the distribution network that contains harmonic current distortion, the true value of the power factor will be affected by the amount $T H D_{\mathrm{I}}$, which is shown as $[19,20]$ :

$$
T P F(\mathrm{i})=D P F(\mathrm{i}) \frac{1}{\sqrt{1+\left\{\frac{T H D_{\mathrm{I}}(\mathrm{i})}{100}\right\}^{2}}} \frac{1}{\sqrt{1+\left\{\frac{T H D_{\mathrm{V}}(\mathrm{i})}{100}\right\}^{2}}}
$$

where,

$D P F(\mathrm{i})=$ Displacement Power Factor for the $\mathrm{i}^{\text {th }}$ measurement step

$D P F(i)$ is the power factor of the fundamental component only, while TPF(i) is a power factor considering the fundamental and harmonic components. In the (5) can be shown that the increase in the value of $T H D_{\text {I }}$ will cause a decrease in the value of $T P F$, which further increases the line current or power losses on the network system.

\subsection{Unbalance Effect on Power Loss}

The unbalance in the system can occur for several reasons, including the load unbalances, the unbalance of the power supply, or the unbalance impedance of power distribution network. In this analysis, the discussion focused on the unbalance power system due to the load unbalance. The load unbalances mainly triggered by the use of 1 phase load that distributed evenly to the entire phase. The percentage of the unbalance of the load current can be expressed by the following equation [21, 22]:

$$
\% I_{\text {unbalance }}=100 x \frac{\text { maximum deviation from avarage current for three }- \text { phase }(\mathrm{R}, \mathrm{S}, \mathrm{T})}{\text { avarage current for three }- \text { phase }(\mathrm{R}, \mathrm{S}, \mathrm{T})}
$$


In this configuration a four-line system is used, each of which transmits the line current in phase R, $\mathrm{S}$, T, and neutral conductor current $I_{\mathrm{N}}$. The relationship between each line phase and neutral current can be given as:

$$
\boldsymbol{I}_{\mathrm{N}}(\mathrm{i})=\boldsymbol{I}_{\mathrm{R}}(\mathrm{i})+\boldsymbol{I}_{\mathrm{S}}(\mathrm{i})+\boldsymbol{I}_{\mathrm{T}}(\mathrm{i})
$$

where,

$\boldsymbol{I}_{\boldsymbol{N}}(\mathrm{i})=$ line neutral current for the $\mathrm{i}^{\text {th }}$ measurement step (Amper)

$\boldsymbol{I}_{\mathrm{R}}(\mathrm{i}), \boldsymbol{I}_{\mathrm{S}}(\mathrm{i}), \boldsymbol{I}_{\mathrm{T}}(\mathrm{i})=$ load current in phase $\mathrm{R}, \mathrm{S}$, T for the $\mathrm{i}^{\text {th }}$ measurement step

Under balance load conditions, the neutral conductor current $\boldsymbol{I}_{\mathrm{N}}$ is zero. The existing of unbalance phase current will cause the current flowing in the neutral conductor. The neutral conductor current will cause power loss by:

$$
P_{\mathrm{N}}(\mathrm{i})=I_{\mathrm{N}}(\mathrm{i})^{2} R_{\mathrm{N}}
$$

where $R_{\mathrm{N}}$ is neutral line resistance, $P_{\mathrm{N}}(\mathrm{i})$ is power loss in the neutral conductor for the $\mathrm{i}^{\text {th }}$ measurement.

In the distribution system containing harmonics, the magnitude of the neutral current $\boldsymbol{I}_{\mathrm{N}}$ will be increased by increasing the component zero sequence component of harmonic currents. The zero sequence component is a harmonic component with a multiple order of 3, known as the Triplen harmonic. The triplen harmonics will increase the current of the neutral conductor and simultaneously increase power loss on this line $[23,24]$. Also, the load current unbalances will also increase power loss on the phase line $[21,25]$.

\subsection{Energy Losses Reduction Potential}

The energy losses in the line phase for the $\mathrm{i}^{\text {th }}$ measurement step $E_{\text {losses }}(\mathrm{i})$ can be calculated as,

$$
E_{\text {losses }}=\sum_{\mathrm{i}=1}^{\mathrm{i}=\mathrm{k}-1}\left\{P_{3 \text { phase-loss }}(\mathrm{i})+P_{\mathrm{N}}(\mathrm{i})\right\} t
$$

where,

$\mathrm{k}=$ amount of measurement step

$\Delta t=$ time interval between 2 steps of measurement (hour)

In this study, $\Delta t$ is set 10 minute or $1 / 6$ hour.

The energy losses reduction potential can be calculated as,

$$
\begin{aligned}
\Delta E_{\text {losses }} & =\left\{\sum_{\mathrm{i}=1}^{\mathrm{i}=\mathrm{k}-1}\left\{P_{3 \text { phase-loss }}(\mathrm{i})+P_{\mathrm{N}}(\mathrm{i})\right\} \Delta t\right\}_{\text {before improvement } \mathrm{PQ}} \\
& -\left\{\sum_{\mathrm{i}=1}^{\mathrm{i}=\mathrm{k}-1}\left\{P_{3 \text { phase-loss }}(\mathrm{i})+P_{\mathrm{N}}(\mathrm{i})\right\} \Delta t\right\}_{\text {after improvement } \mathrm{PQ}}
\end{aligned}
$$

\section{RESULTS AND ANALYSIS}

The results of the analysis of power loss and energy losses in the distribution lines of buildings in the Faculty of Engineering, Andalas University in conditions without/with power quality improvements were presented and discussed in this section. In this analysis, improvements in power quality through increased power factor and load balancing were carried out to the maximum, while the harmonic current reduction was carried out for THDI values exceeding $5 \%$.

Figure 7 shows the results of an analysis of the effect of power quality improvement on power loss along the phase line and neutral conductors on the distribution line of mechanical engineering building (line \#1) during one week. As shown in Figure 8, the effect of power quality improvement on the power loss reduction in this building is relatively significant. It is mainly due to variations in unbalance and THD of load currents relatively large, as described in Figure 2.

The analysis results of the effect of improving power quality to power loss on the distribution line of electrical engineering building (line \#2) during one week are shown in Figure 8. As shown in this figure, power loss on Thursday is almost as small as power loss on Saturday and Sunday. This situation occurs because the electricity consumption is relatively small on Thursday, which is a public holiday. Whereas every Tuesday is usually conducted practicum activities in the laboratory, but at the time of measurement, there is no schedule 
for practice. Therefore, power losses on Tuesday are also relatively small. In this building, the balance and harmonic load currents also have a significant effect on increasing losses in the distribution line.

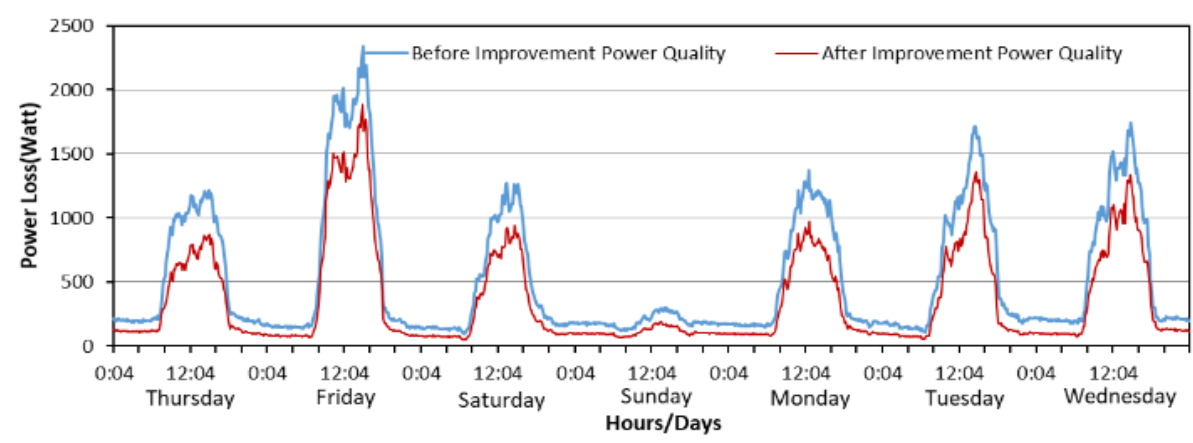

Figure 7. Analysis result of the effect of power quality improvement to power loss reduction on the distribution line \#1during one week

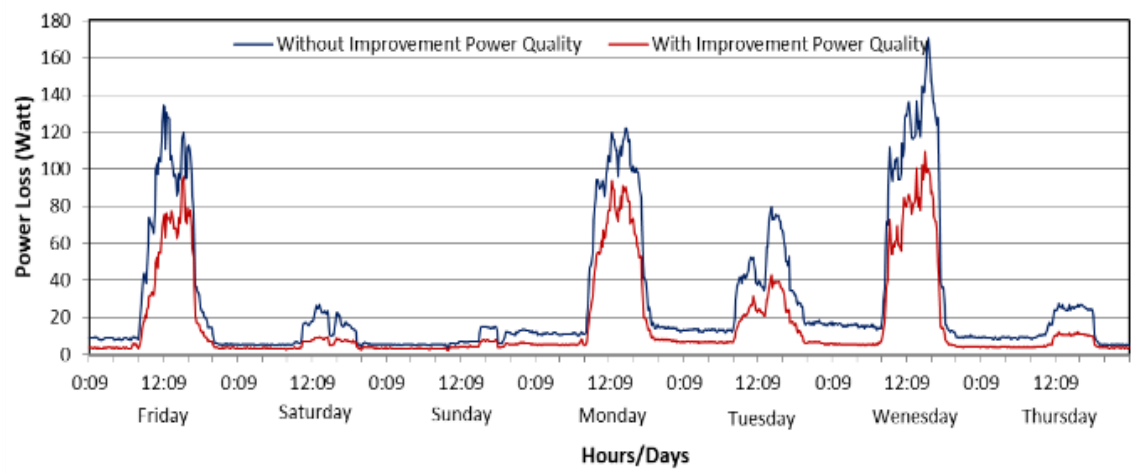

Figure 8. Analysis result of the effect of power quality improvement to power loss reduction on the distribution line \#2 during one week

Figure 9 has shown the results of an analysis of the effect of improving power quality to the power loss on the distribution line of the Faculty Administration building (line \#3) during 1 week. As shown in this figure, power loss on this line is relatively low because the load current is relatively small, and the line length is the only $57 \mathrm{~m}$. However, in its load, there is a very large unbalance, with the percentage imbalance reaching $127.9 \%$ (see Figure 4). It will produce a very significant effect on the decrease in power loss if a percentage of the unbalance is reduced.

The results of the analysis of the effect of power quality improvement to the power loss on the distribution line of the Civil Engineering building group (line \#4) during 1 week are shown in Figure 10. The power losses in these group buildings are the biggest compared to other buildings. It is due to the large load currents and the distribution line length reaching $190 \mathrm{~m}$. However, this building has better power quality than other buildings, so the percentage reduction in power losses will be lower, as shown in Figure 10.

Table 2 has present the results of energy losses reduction analysis through increasing power quality on the distribution line of each building in the Faculty of Engineering, Andalas University. The biggest energy losses occur on the distribution line of Civil Engineering Group buildings, with energy losses reaching 88478.47 Watt-hour during one week. Meanwhile, the smallest energy losses occur in the distribution line of Administration Faculty Building, with energy losses of 2663.02 Watt-hour during one week. This condition occurs because the Civil Engineering building group consists of 3 buildings with the largest electric load and longest distribution line length, which results in producing large energy losses. However, Civil Engineering groups building has the smallest percentage of energy losses reduction potential $(32.81 \%)$, and the Administration Faculty building has the largest percentage of energy losses reduction potential (52.62\%). This condition can be understood because Civil Engineering groups building has a relatively better PQ variable, with an average THDI of $10.15 \%$, current unbalance of $21.27 \%$, average power factor of $80.88 \%$. Meanwhile, 
the Faculty Administration Building administration has a poor PQ variable, with an average THDI of $44.29 \%$ and current unbalance of $34.55 \%$.

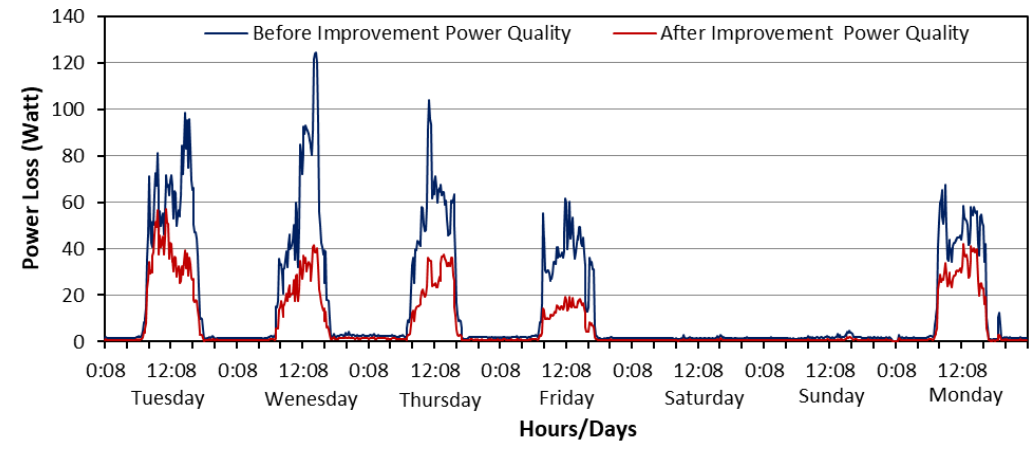

Figure 9. Analysis result of the effect of power quality improvement to power loss reduction on the distribution line \#3 during one week

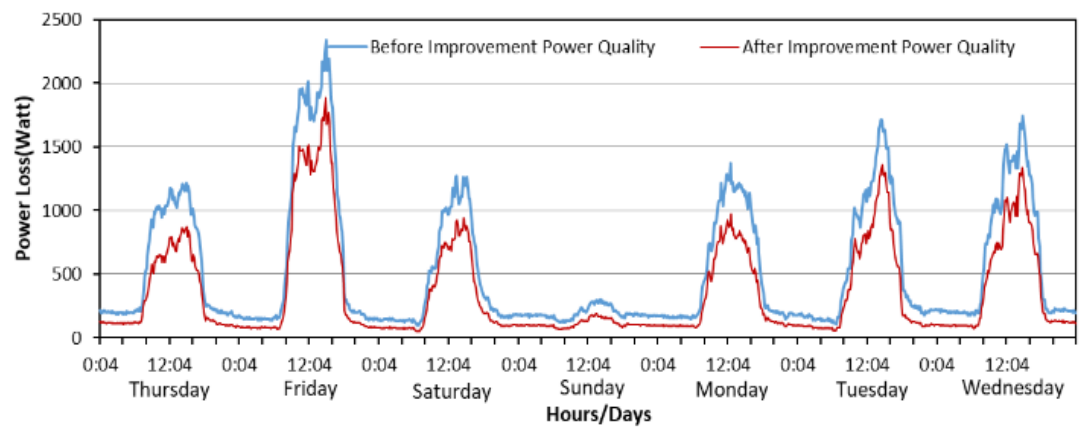

Figure 10. Analysis result of the effect of power quality improvement to power loss reduction on the distribution line \#4 during one week

Table 2. The Results of the Reduction of Electric Energy Losses Through PQ Improvement During One Week

\begin{tabular}{|c|c|c|c|c|}
\hline \multirow[t]{2}{*}{ Buildings } & \multicolumn{2}{|c|}{ Energy Losses (Watt-hour) } & \multicolumn{2}{|c|}{$\begin{array}{c}\text { Energy Losses Reduction } \\
\text { Potential }\end{array}$} \\
\hline & without PQ improvement & with PQ improvement & Watt-hour & $\%$ \\
\hline Mechanical Eng. & 11725.04 & 7151.49 & 4.573 .55 & 39.01 \\
\hline Electrical Eng. & 4796.01 & 2747.09 & 2048.92 & 42.72 \\
\hline Admin. Faculty & 2663.02 & 1261.70 & 1401.32 & 52.62 \\
\hline Civil Eng. Groups & 88478.47 & 59447.93 & 29030.54 & 32.81 \\
\hline Faculty Total & 107662.54 & 70608.21 & 37054.33 & 34.42 \\
\hline
\end{tabular}

\section{CONCLUSION}

The energy losses reduction potential of distribution line on buildings in Engineering Faculty, Andalas University has been successfully analyzed in this study. From the analysis results, an increase in power quality with the standard expected during one week will cause a decrease in energy loses from 107,662.54 Watt-hour to 70,608.21 Watt-hour, with total energy losses reduction by $37,054.33$ Watt-hour or $34.42 \%$ from total energy losses on the distribution line. The amount of reducing energy losses reduction on the distribution line for each building is proportional to the power quality level of the load power. The biggest percentage reduction in energy losses has occurred in the Faculty Administration building, while the lowest percentage of energy losses has occurred in the Civil Engineering Building Group. The amount of energy losses that can be reduced through the path of increasing PQ is smaller than other energy losses reduction pathways, such as replacing inefficient equipment with more efficient equipment and waste energy activities. However, this reduction line must remain a priority because of the poor power quality can also cause interference with the supply of electrical energy.

Analysis of energy losses reduction potential on the distribution line of campus building... (Andi Pawawoi) 


\section{ACKNOWLEDGEMENTS}

Authors would like thanks to Andalas University for the financial support this work, through KRP1GB Funding No. 02/UN.16.17/PP.RGB/LPPM/2018.

\section{REFERENCES}

[1] Oyedepo, S.O. et.al.,"Assessment of energy saving potentials in Covenant University, Nigeria," Energy Engineering, vol. 113, no. 3, pp. 7-26, 2016.

[2] M. Esmaeil Honarmand, et al., "Visibility of Electric Distribution Utility Performance to Manage Lossand Reliability Indices", J Electr Eng Technol. 2017; 12(5): pp. 1764-1776.

[3] Shyr, Wen-Jye et al., "Application of an energy management system via the internet of things on a University Campus," Eurasia Journal of Mathematics, Science and Technology Education, vol. 14, no. 5, pp. 1759-1766, 2018. doi:10.12973/ejmste/80790.

[4] Emeakaroha, Anthony, Chee Ang, and Yong Yan., "Challenges in improving energy efficiency in a University Campus through the application of persuasive technology and smart sensors," Challenges Journal, vol. 3, no 2, pp 290-318, 2012.

[5] Mehrdad Ahmadi Kamarposhti., "Power quality compensation in distribution system based on instantaneous power theory and recursive fuzzy proportional-integral controller," International Journal of Electrical and Computer Engineering, vol. 8, No. 1, pp. 538-543, 2018.

[6] Alena Otcenasova, et al., "The Influence of Power Quality Indices on Active Power Losses in a Local Distribution Grid", Energies 2019, 12, 1389; doi:10.3390/en12071389.

[7] Alexander Kusko and Marc T. Thompson, "Power quality in electrical systems," The McGraw Hill, 2007.

[8] C. Sankaran, "Power Quality", CRC Press, 2002.

[9] Bantras, T., et al., "Estimation and classification of power losses due to reduced power quality," IEEE Power and Energy Society General Meeting, IEEE, 2012.

[10] Mujawar, Irfan I., et al., "Power quality audit of NKOCET-a case study," International Conference on Energy Systems and Applications, IEEE, 2015.

[11] Ghorbani, M. Jawad, and Hossein Mokhtari, "Impact of harmonics on power quality and losses in power distribution systems," International Journal of Electrical \& Computer Engineering, vol. 5, no 1, pp. 2088-8708, 2015.

[12] D, Danalakshmi \& Bugata, Srinivas \& J, Kohila, "A control strategy on power quality improvement in consumer side using custom power device," Indonesian Journal of Electrical Engineering and Computer Science, vol. 15, pp. 80-87, 2019.

[13] A. Sharma, et al., "A review on economics of power quality: Impact, assessment and mitigation", Renewable and Sustainable Energy Reviews 88 (2018), pp. 363-372.

[14] Gabriel V. POP, et al., "Calculation of Power Losses in Unbalanced and Harmonic Polluted Electric Networks", 7th International Conference on Electromechanical and Power Systems, 2009, Italia.

[15] Schneider, "Power Quality \& Energy Efficiency Solutions", 2012.

[16] Jurica Perko, et al., "Comparative Analysis of Power Quality Indices for Different Lighting Techniogies in Public Lightning”, International Journal of Electrical and Computer Engineering (IJECE), Vol. 8, No. 2, April 2018, pp. 880-887.

[17] J. Jayachandran, S. Malathi, "Improved power quality buck boost converter for SMPS", International Journal of Electrical and Computer Engineering (IJECE), Vol. 8, No. 2, April 2018, pp. 880-887.

[18] Jorge I. Silva, et al., "Effects of power electronics devices on the energy quality of an administrative building", International Journal of Power Electronics and Drive System (IJPEDS), Vol. 10, No. 4, December 2019, pp. 19511960.

[19] Grady, W. Mack, and Robert J. Gilleskie, "Harmonics and how they relate to power factor," Proceedings of PQA93, 1993.

[20] Francis M. F., and P.S. Chandramohanan N., "A New Expression for Power Factor under Nonsinusoidal Conditions", 2011 IEEE PES Innovative Smart Grid Technologies.

[21] Hossein Arghavani \& Mitra Peyravi, "Unbalanced current-based tariff," 24th International Conference \& Exhibition on Electricity Distribution (CIRED), pp. 883-885, 2014.

[22] Bina, M. Tavakoli, and A. Kashefi, "Three-phase unbalance of distribution systems: Complementary analysis and experimental case study," International Journal of Electrical Power \& Energy Systems, vol. 33, no. 4, pp. 817-826, 2011.

[23] Eldin, A. Fatehy, A \& Rushdy, K, "The Analysis of Mgnification of Neutral Current In The Presence Of Power Quality Problems," 23rd International Conference on Electricity Distribution, Lyon, 2015.

[24] Eduful, G \& Kingsford J.A. Atanga, "Analysis of High Neutral Currents and Harmonic Impacts on Losses and Capacities of Distribution Transformers," Proceedings of the World Congress on Engineering, vol. 1, 2016.

[25] Chen, T-H., "Evaluation of line loss under load unbalance using the complex unbalance factor," IEE ProceedingsGeneration, Transmission and Distribution, vol. 142, no. 2, pp. 173-178, 1995. 